\title{
Análise de parâmetros bioquímicos séricos e urinários em atletas de meia maratona
}

\author{
Biochemist plasmatic and urinary parameters \\ analisys in marathon athletes
}

Luciano de Oliveira Siqueira', Tiane Muccini', landra Dall Agnol', Lauren Filla', Paula Tibbola', Andiara Luvison', Leandro Costa', José Cláudio Fonseca Moreira ${ }^{2}$

${ }^{1}$ Curso de Farmácia, Instituto de Ciências Biológicas, Universidade de Passo Fundo (UPF), Passo Fundo, RS, Brasil ${ }^{2}$ Departamento de Bioquímica, Instituto de Ciências Básicas da Saúde, Universidade Federa do Rio Grande do Sul (UFRGS), Porto Alegre, RS, Brasil
Correspondência para: Luciano de Oliveira Siqueira Universidade de Passo Fundo, Curso de Farmácia BR 285, Km 171 Campus I - São José 99010-210 - Passo Fundo, RS, Brasil luciano@upf.br

Recebido em 6/Mar/2009 Aceito em 27/Jul/2009

\begin{abstract}
RESUMO
Objetivo: O objetivo do presente estudo foi analisar marcadores bioquímicos como marcadores de desempenho atlético, à luz de um contexto clínico e atlético. Métodos: Foram coletadas amostras de sangue periférico $(8 \mathrm{~mL})$ e de urina $(50 \mathrm{~mL})$ de 20 maratonistas profissionais em repouso e 15 minutos após meia maratona. Em seguida, realizaram-se hemograma, exame de urina e análise de marcadores bioquímicos de função renal, lesão muscular e lipidograma. Resultados: A análise estatística dos resultados mostrou um aumento significativo $(p<0,05)$ na atividade sérica das enzimas CK, CK-MM, CK-MB e LDH; na concentração sérica de creatinina, ferro sérico, leucócitos e neutrófilos. Por outro lado, triglicérides, VLDL e ácido úrico sérico apresentaram um decréscimo significativo. Conclusão: 0 presente estudo mostra que os atletas analisados apresentam alterações nos parâmetros bioquímicos de sangue e urina após uma prova dessa modalidade, o que demonstra a importância da realização de exames laboratoriais como forma de diagnóstico de distúrbios bioquímicos silenciosos. Arq Bras Endocrinol Metab. 2009;53(7):844-52.

Descritores

Atletismo; análise química do sangue; lesões
\end{abstract}

\begin{abstract}
Objective: The aim of this study was to analyze biochemical markers as indicators of athletic performance, in light of a clinical context and athletic. Methods: Samples of peripheral blood $(8 \mathrm{~mL})$ and urine $(50 \mathrm{~mL})$ were collected from 20 marathon athletes at rest and 15 minutes after half marathon. Following, examination of blood, urine and serum markers of renal function, muscle damage and lipidic profile was carried out. Results: Statistical analysis of the results showed a significant increase $(p<0.05)$ in serum activity of the enzymes CK, CK-MM, CK-MB and $\mathrm{LDH}$, serum creatinine and iron, leukocyte count and neutrophils. Furthermore, triglycerides, VLDL, uric acid in serum showed a significant decrease. Conclusion: This study shows that athletes of marathon show changes in biochemical parameters of blood and urine after competing in this modality, which demonstrates the importance of carrying out laboratory tests as diagnosis for silent biochemical disorders. Arq Bras Endocrinol Metab. 2009;53(7):844-52.
\end{abstract}

Keywords

Sports; blood chemical analysis; injuries

\section{INTRODUÇÃO}

$\mathrm{O}$ organismo dispõe de diversos mecanismos de produção de energia, síntese, degradação e remoção de compostos que compreendem o metabolismo basal de um indivíduo. A prática esportiva requer uma adap- tação metabólica para atender à demanda energética acelerada, bem como a remoção de metabólitos desnecessários para o organismo. A adaptação orgânica depende do tipo, da intensidade e da duração do exercício (1-7). Para um bom condicionamento, é necessário que as funções orgânicas do indivíduo estejam plenamente 
ajustadas, pois a atividade motora implica graus de sobrecargas diferenciadas sobre os sistemas que compõem o corpo humano, marcadamente o muscular e o cardiorrespiratório $(1,4,5,7)$.

Estudos com atletas de resistência apontam modificações bioquímicas típicas, em 12 a 24 horas após a prática esportiva, caracterizadas por aumento da atividade da lactato desidrogenase ( $\mathrm{LDH})$, creatina quinase total e frações (CK-MM e MB, respectivamente). Muitas vezes, a elevação da atividade/concentração de alguns marcadores bioquímicos de lesão não acompanha modificações significativas no eletrocardiograma, no exame clínico ou no desempenho atlético. Essa condição pode ser exemplificada pelo fato de que alguns atletas podem apresentar uma elevação de cerca de 30 vezes na atividade da CK após 24 horas do esforço sem qualquer comprometimento no seu desempenho ou saúde. Por outro lado, um quadro de rabdomiólise pode ser detectado em atletas cuja CK está aumentada em 15 vezes ou ainda menos. Isso mostra a necessidade da intervenção multiprofissional, uma vez que ainda se desconhece o verdadeiro limite bioquímico entre a adaptação ao exercício e o início de overtraining (2,4-14).

Estudos envolvendo valores de referência para parâmetros bioquímicos e hematológicos de atletas profissionais durante uma sessão de treinamento ainda são inconclusivos (3-7). Isso se deve ao fato de que algumas alterações bioquímicas são passíveis de influência do gênero, variação cronobiológica, circadiana, repouso prévio, intensidade do treinamento, sazonalidade, condições climáticas, hidratação, entre outros. Além disso, diversos relatos apontam alterações bioquímicas normais que não representam alteração patológica, dificultando o diagnóstico de lesões silenciosas (6-14). Dessa forma, o diagnóstico clínico de microlesão e overtraining deve sempre ser realizado considerando-se aspectos bioquímicos, clínicos e de desempenho atlético $(3,4,6,10-13)$.

Apesar de estudada exaustivamente desde a década de 1980, ainda há uma grande carência de estudos bioquímicos em atletas sob condições específicas de treinamento, esforço e clima. Essa carência impede a realização de metanálises confiáveis para obtenção de valores bioquímicos de referência em diferentes situações de esforço. Partindo desses princípios, o objetivo do presente estudo foi analisar as alterações bioquímicas agudas de parâmetros laboratoriais de atletas profissionais em início de temporada e submetidos a uma prova de meia maratona.

\section{MATERIAL E METODOLOGIA}

\section{Casuística}

Foram incluídos no estudo 20 maratonistas profissionais do sexo masculino. Realizou-se uma anamnese, constituída de uma entrevista padrão a respeito do uso de medicamentos, suplementos, tempo de treinamento e distância percorrida por semana. Todos treinavam diariamente havia mais de dois anos, usavam tênis apropriado para corrida, com prévia ingestão de refeição leve, e que concluíram a prova até 15 minutos após o primeiro colocado. Nenhum deles era fumante ou fazia uso de medicação no momento da análise, além de não possuírem histórico de doenças crônicodegenerativas.

O protocolo do estudo foi previamente submetido e aprovado pelo Comitê de Ética em Pesquisa da Universidade de Passo Fundo, segundo o regulamento 196/1996 do Conselho Nacional de Saúde sob registro $\mathrm{n}^{\circ} 526 / 2005$. Todos os atletas aceitaram participar do estudo voluntariamente, após terem sido informados dos objetivos e possíveis riscos do estudo. A seguir, foi assinado o termo de consentimento livre e informado conforme o Código de Nuremberg (1947), Declaração dos Direitos do Homem (1948) e a Declaração de Helsinque.

\section{Condições ambientais}

A meia maratona ocorreu no turno da manhã, em pista asfaltada a uma altitude de $687 \mathrm{~m}$ do nível do mar, temperatura ambiente de $5{ }^{\circ} \mathrm{C}$, clima seco e ensolarado. Os atletas realizaram a prova com roupas leves e percorreram $21 \mathrm{~km}$ num tempo médio de $70 \pm 7$ minutos.

\section{Análises laboratoriais}

\section{Sangue}

Amostras de sangue foram coletadas, com antissepsia prévia da fossa antecubital dos atletas, 15 minutos antes do aquecimento para a corrida e 15 minutos após seu término. Parte da amostra colhida $(8 \mathrm{~mL})$ foi acondicionada em tubo de ensaio sem anticoagulante e centrifugada a $1.500 \mathrm{rpm}$ por 15 minutos. O soro extraído foi acondicionado em frascos de Eppendorf para posterior dosagem bioquímica de glicose, ácido úrico, creatinina, proteínas, ureia, creatina quinase total e fração $\mathrm{MB}$, lactato desidrogenase, fosfatase alcalina, triglicérides, colesterol total e frações (HDL, LDL e VLDL), ferro sérico e capacidade ferropéxica (TIBC). Utilizaram-se 
kits da marca Labtest Diagnóstica ${ }^{\circledR}$ e Biotécnica ${ }^{\circledR}$ em protocolos específicos para sua determinação em equipamento semiautomatizado da marca Labquest ${ }^{\oplus}$. Foram acondicionados $2 \mathrm{~mL}$ de sangue total em um frasco contendo $2 \mathrm{mg} / \mathrm{mL}$ de etilenodiaminotetracético (EDTA) para análise hematológica. O hemograma foi realizado mediante contagem eletrônica de células por análise de impedância (Sysmex XS $1000{ }^{\circledR}$ ). A contagem diferencial dos leucócitos foi realizada por análise microscópica de 200 células (Nikon Eclipse $600^{\circledR}$ ) em uma distensão sanguínea corada pelo método de Romanowsky $\left(\right.$ Merck $\left.^{\circledR}\right)$.

\section{Urina}

Coletaram-se aproximadamente $50 \mathrm{~mL}$ do jato médio de urina de cada indivíduo em repouso e até 15 minutos após a meia maratona. As amostras foram acondicionadas em frascos padrão que foram transportados do local de coleta até o laboratório da Faculdade de Farmácia da Universidade de Passo Fundo em temperatura controlada. Imediatamente, as amostras foram processadas mediante análise físico-química e microscópica do sedimento, conforme recomendado pela ABNT-CB 36. As amostras foram centrifugadas a $1800 \mathrm{rpm}$ por dez minutos e $1 \mathrm{~mL}$ do sobrenadante foi retirado para posterior análise bioquímica de proteínas totais, ácido úrico, creatinina e ureia.

Realizou-se a análise físico-química da urina mediante observação visual do aspecto e coloração desta. A densidade foi determinada com refratômetro $\left(\mathrm{LF}^{\oplus}\right)$. Procedeu-se à análise química utilizando fita de polieletrólitos (ComburTest Dade-Behring ${ }^{\circledR}$ ) para detecção semiquantitativa de proteínas, glicose, nitrito, bilirrubina, $\mathrm{pH}$, corpos cetônicos, leucócitos, sangue e urobilinogênio na amostra de urina não centrifugada. A análise microscópica foi realizada na urina após centrifugação para quantificação de células epiteliais, cristais, leucócitos, hemácias, bactérias, filamento de muco e cilindros.

O presente estudo foi limitado por variáveis inerentes ao processo analítico. No entanto, essas limitações foram minimizadas realizando-se os testes em duplicata e utilizando-se soro controle como rastreamento de possíveis falhas analíticas e para obtenção de resultados consistentes.

\section{Análise estatística}

Para o exame físico-químico da urina, elaborou-se uma escala de coloração expressa como: amarelo-claro, ama- relo, amarelo-escuro e âmbar. Para análise estatística, essa escala foi substituída por números: 1, 2, 3 e 4, respectivamente.

Da mesma forma ocorreu com os resultados que expressam o aspecto da amostra (límpido, pouco turvo, turvo, muito turvo e leitoso), os quais foram substituídos por $0,1,2,3$ e 4 , respectivamente. A análise química da urina foi procedida pelo método semiquantitativo mediante reação com fita de polieletrólito (Combur Test Dade Behring $\left.{ }^{\circledR}\right)$, sendo os resultados expressos por ausência, traços, 1, 2, 3 e 4 cruzes. Estes, então, foram substituídos por $0,1,2,3,4$ e 5 , respectivamente, exceto para valores de $\mathrm{pH}$.

Os resultados dos parâmetros do exame microscópico do sedimento urinário foram expressos em número de estruturas observadas por campo de microscopia em 100X (células epiteliais, cristais, filamento de muco e cilindros) e 400X (hemácias, leucócitos e bactérias). No caso de células epiteliais, os resultados foram expressos como raras $(0-4 \mathrm{p} / \mathrm{c})$, algumas $(5-8 \mathrm{p} / \mathrm{c})$, diversas $(9-12 \mathrm{p} / \mathrm{c})$ e numerosas $(>13)$. Para análise dos resultados, atribuíram-se valores $1,2,3$ e 4 , respectivamente para cada conceito. Para análise quantitativa de filamento de muco, os conceitos: ausente, pequena, moderada e grande quantidade foram substituídos por $0,1,2$ e 3 .

Foram analisados três tipos de cristais: urato amorfo, oxalato de cálcio e ácido úrico. Para estes foram usados os conceitos: ausência, pequena, moderada e grande quantidade, e também substituídos por números 0,1 , 2 e 3 , respectivamente.

Os dados foram testados quanto à sua normalidade mediante análise de Kolmogorof-Smirnoff. Em segui$\mathrm{da}$, os resultados foram analisados estatisticamente por comparação de médias utilizando o teste $t$ de Student para amostras pareadas (dados paramétricos) e teste de Wilcoxon-Mann-Whitney (dados não paramétricos) no pacote estatístico do SPSS 13.0, considerando-se p < 0,05 como nível mínimo de significância. Os resultados foram expressos como média \pm erro padrão.

\section{RESULTADOS}

A tabela 1 apresenta a caracterização antropométrica e status de performance física dos atletas.

A tabela 2 mostra os resultados dos parâmetros bioquímicos dos atletas em repouso e 15 minutos após o término da prova. Em comparação aos valores basais, os resultados mostram um aumento significativo 
na concentração sérica de HDL, creatinina, CK total e frações MM e MB, ferro sérico. Por outro lado, mostram também uma diminuição significativa na concen-

Tabela 1. Caracterização antropométrica e status de desempenho físico dos atletas: resultados expressos como média \pm erro padrão

\begin{tabular}{lc}
\hline Variável & Caracterização \\
\hline "n" amostral & 20 atletas \\
Gênero & Masculino \\
Idade & $35,5 \pm 10$ anos \\
Altura & $174 \pm 6 \mathrm{~cm}$ altura \\
Peso & $63,3 \pm 6,3 \mathrm{~kg}$ \\
Índice de massa corporal (IMC) & $21 \pm 1,2 \mathrm{~kg} / \mathrm{m}^{2}$ \\
Tempo de treinamento & $13,2 \pm 7$ anos \\
\hline
\end{tabular}

tração de triglicérides, colesterol LDL, ácido úrico sérico $(\mathrm{p}<0,05)$.

A análise hematológica (Tabela 3 ) mostra uma elevação na contagem de leucócitos, monócitos e neutrófilos, acompanhada de uma redução da contagem de linfócitos e eosinófilos $(\mathrm{p}<0,05)$ após a prova.

A análise dos resultados de parâmetros urinários (Tabela 4) mostrou uma elevação significativa na concentração de ácido úrico e cilindros $(\mathrm{p}<0,05)$.

A análise estatística para dados não paramétricos demonstrada na tabela 5 aponta um aumento estatisticamente significativo $(\mathrm{p}<0,05)$ para a presença de filamento de muco, turvação, sangue e proteínas totais na urina.

\begin{tabular}{|c|c|c|c|}
\hline & Repouso & Após esforço & Valor de $\mathbf{p}^{*}$ \\
\hline Triglicerídeos (mg/dL) & $85,8 \pm 8,4$ & $69,1 \pm 5,2$ & 0,04 \\
\hline Colesterol LDL (mg/dL) & $155,4 \pm 10,4$ & $110 \pm 11,1$ & 0,03 \\
\hline Colesterol HDL (mg/dL) & $42,9 \pm 1,3$ & $47 \pm 2,7$ & 0,001 \\
\hline Ácido úrico sérico (mg/dL) & $4,97 \pm 1,7$ & $3,51 \pm 1,2$ & 0,005 \\
\hline Creatinina sérica (mg/dL) & $0,85+0,18$ & $1,14 \pm 0,17$ & 0,04 \\
\hline Creatina quinase total sérica (U/L) & $84,9 \pm 48,1$ & $198,2 \pm 163,9$ & 0,01 \\
\hline Creatina quinase mm sérica (U/L) & $58,3 \pm 39,4$ & $164,1 \pm 153,2$ & 0,03 \\
\hline Creatina quinase mb sérica (U/L) & $28,8 \pm 12,4$ & $44,7 \pm 17,0$ & 0,04 \\
\hline Relação creatina quinase mb/creatina quinase total & $33,9 \pm 25$ & $22,5 \pm 4,2$ & 0,02 \\
\hline Ferro sérico ( $\mu \mathrm{g} / \mathrm{dL})$ & $19,5 \pm 3,7$ & $23,9 \pm 2,0$ & 0,02 \\
\hline IST (\%) & $5,7 \pm 1,3$ & $7,6 \pm 1,4$ & 0,02 \\
\hline
\end{tabular}

* $p<0,05$ em relação ao repouso pela análise do teste de $t$ de Student para amostras pareadas.

IST: índice de saturação da transferrina.

Tabela 3. Análise de parâmetros hematológicos de maratonistas profissionais em repouso e 15 minutos após a realização de meia maratona. Resultados expressos como média \pm erro padrão

\begin{tabular}{lccc}
\hline & Repouso & Após esforço & Valor de p* \\
\hline Leucometria (cels/uL) & $6.300 \pm 227$ & $13.800 \pm 818$ & $<0,0001$ \\
Monócitos (uL) & $323,4 \pm 59$ & $476,2 \pm 56,8$ & 0,04 \\
Linfócitos (\%) & $32,9 \pm 2,7$ & $21 \pm 2,2$ & 0,001 \\
Linfócitos (UL) & $2056,4 \pm 192$ & $2932 \pm 406$ & 0,03 \\
Eosinófilos (\%) & $2,3 \pm 0,5$ & $1,1 \pm 0,2$ & 0,02 \\
Neutrófilos segmentados (\%) & $49,5 \pm 3,4$ & $59,8 \pm 2,2$ & 0,01 \\
Neutrófilos segmentados (uL) & $2932,6 \pm 270$ & $8323,8 \pm 607$ & $<0,0001$ \\
Neutrófilos bastonetes (\%) & $4,3 \pm 0,8$ & $13,9 \pm 1,4$ & $<0,0001$ \\
Neutrófilos bastonetes (UL) & $398,2 \pm 135$ & $1952 \pm 262$ & $<0,0001$ \\
Plaquetas (uL) & $239,2 \pm 12$ & $287,7 \pm 11$ & 0,04 \\
\hline
\end{tabular}

* $p<0,05$ em relação ao repouso pela análise do teste de $t$ de Student para amostras pareadas. 
Tabela 4. Análise de parâmetros urinários de maratonistas profissionais em repouso e 15 minutos após a realização de meia maratona. Resultados expressos em média \pm erro padrão

\begin{tabular}{lccc}
\hline & Repouso & Após esforço & Valor de $\mathbf{p}^{*}$ \\
\hline Cilindros urinários (mín.) & $0,0 \pm 0,0$ & $9,0 \pm 11,8$ & 0,004 \\
Cilindros urinários (máx.) & $0,0 \pm 0,0$ & $17 \pm 21$ & 0,002 \\
Leucócitos urinários (mín.) & $0,0 \pm 0,0$ & $1,0 \pm 1,9$ & 0,05 \\
Leucócitos urinários (máx.) & $2,0 \pm 0,3$ & $7,0 \pm 6,8$ & 0,002 \\
Ácido úrico urinário (mg/mg de creatinina) & $0,3+0,289$ & $0,58+0,67$ & 0,03 \\
\hline
\end{tabular}

${ }^{*} p<0,05$ em relação ao repouso pela análise do teste de $t$ de Student para amostras pareadas.

Tabela 5. Análise de parâmetros urinários de maratonistas profissionais em repouso e 15 minutos após a realização de meia maratona. Resultados expressos em média \pm erro padrão

\begin{tabular}{lccc}
\hline & Repouso & Após esforço & Valor de $\mathbf{p}^{\text {* }}$ \\
\hline Cristais urato amorfo & $1,0 \pm 1,4$ & $0,4 \pm 0,9$ & 0,01 \\
Filamento de muco & $0,1 \pm 0,2$ & $1,0 \pm 1,3$ & $<0,001$ \\
Aspecto/turbidez & $0,0 \pm 0,0$ & $1,0 \pm 1,0$ & 0,008 \\
Sangue & $0,2 \pm 0,6$ & $2,0 \pm 2,1$ & 0,006 \\
Proteínas & $0,0 \pm 0,0$ & $1,0 \pm 0,8$ & $<0,001$ \\
\hline
\end{tabular}

${ }^{*} \mathrm{p}<0,05$ em relação ao repouso pela análise do teste de Wilcoxon-Mann-Whitney para dados não paramétricos.

\section{DISCUSSÃO}

O exercício físico extenuante pode causar uma sobrecarga nos músculos. Por exigir uma força excessivamente maior que a necessidade habitual e os sistemas contráteis podem se romper estruturalmente $(6,13-17)$. Em consequência, uma maior infiltração de neutrófilos é evidenciada, com subsequente liberação de proteínas celulares para a circulação, como, por exemplo, a creatina quinase (13-17). Dessa forma, o aumento da atividade plasmática de enzimas musculares, como lactato desidrogenase (LDH), CK total e frações, pode ser uma resposta fisiológica típica diante de exercícios físicos intensos e que geralmente podem ser usados como marcadores de lesão muscular (13-19). O pico de atividade dessas enzimas ocorre dentro de 12 a 24 horas; no entanto, o foco deste estudo foi analisar as adaptações agudas que ocorrem num período inferior a 15 minutos.

Estudos prévios realizados em maratonistas por França e cols. mostram uma elevação de $110 \%$ na atividade de CK total, $30 \%$ a $40 \%$ na $\mathrm{LDH}$ e $40 \%$ para CK-MB 24 a 60 horas após uma prova de maratona ou outro tipo de prática esportiva de elite (6,13-19). Esses resultados corroboram os achados do presente estudo, que apontaram um aumento de aproximadamente $120 \%$ para CK-total, 180\% para CK-mm, 85\% para CK-mb e $50 \%$ para $\mathrm{LDH}$, mostrando que uma análise aguda de amostras biológicas pode contribuir significativamente para o diagnóstico de modificações bioquímicas induzidas pelo esporte.

$\mathrm{Na}$ medicina esportiva, a atividade da enzima CK total no soro é considerada um importante marcador de lesão muscular, no entanto, seu valor isolado como marcador é questionável, pois é um parâmetro bastante indireto e pouco específico. Além disso, variações na atividade da CK diferem marcadamente de acordo com as condições de realização do exercício, carga de esforço, intensidade, duração, bem como do histórico de treinamento dos atletas e de características físicas individuais (13-19). O dano muscular causado pelo exercício é caracterizado por diminuição na produção de força muscular, aumento da atividade sérica da $\mathrm{CK}$, rompimento de fibras musculares, inflamação e aumento na atividade de enzimas proteolíticas. Se a carga de exercício for repetida ao longo do tempo, o dano muscular é reduzido e o atleta desenvolve uma adaptação dos músculos esqueléticos, caracterizada por uma redução na liberação de CK para a corrente circulatória. A análise estatística dos resultados da atividade da CK-MM mostrou um aumento significativo $(\mathrm{p}<0,05) 15$ minutos após a meia maratona. A liberação de CK-MM para a corrente circulatória é mais específica de sobrecarga muscular quando comparada à CK total (13-19).

A análise estatística da atividade da CK-MB mostrou um significativo aumento $(\mathrm{p}<0,05)$ em sua atividade. 
O diagnóstico de dano cardíaco em maratonistas é complexo, pois a elevação da atividade da CK-MB também ocorre em corredores assintomáticos e que apresentam exames cardiológicos normais após a corrida. Esse aumento pode ser explicado pela ocorrência de uma lesão silenciosa do músculo esquelético que supera a liberação da CK-MB proveniente do coração (13-20). O aumento na concentração sérica de CK-MB também pode acontecer devido às formas atípicas de $\mathrm{CK}$, como, por exemplo, a macro-CK, que é um complexo formado por CK-BB ligado a imunoglobulinas (IgA, IgG), cuja presença no soro dos atletas pode provocar uma aparente elevação na atividade de CK-MB.

Outra causa de elevação da CK é o microtrauma adaptativo, que é um tipo de lesão que faz parte integral do processo de adaptação a certos treinamentos ou uma consequência inevitável a eles. Em atletas altamente treinados, o microtrauma adaptativo pode ser uma resposta constante, capaz de acelerar o turnover das fibras musculares. Diversas hipóteses foram estabelecidas para explicar o microtrauma adaptativo, dentre elas, pressupõe-se a ocorrência de uma sobrecarga metabólica em que a necessidade por ATP se tornaria mais alta do que a sua taxa de produção; outra teoria propõe que a lesão muscular possa ser causada por forças mecânicas, como os presentes na contração excêntrica, capazes de romper a arquitetura muscular; outra propõe a elevação de mediadores de inflamação e estresse oxidativo entre outros (13-19). Assim, esses achados mostram que a análise de marcadores bioquímicos de lesão, inflamação e desempenho atlético deve ser investigada à luz de um contexto clínico do atleta, bem como o seu desempenho após uma competição ou sessão de treinamento. Uma interpretação criteriosa deve ser aplicada no intuito de evitar conclusões equivocadas acerca de uma condição típica de esforço, quando comparada a uma condição patológica.

Brites e cols. mostraram que o exercício físico aeróbico está associado a um perfil lipídico menos aterogênico e com um risco cardiovascular reduzido. Durante um treino de resistência, a lipase lipoproteica exerce função regulatória induzindo uma modificação e redistribuição intermolecular do colesterol e suas subfrações, com aumento do HDL-C, que é compatível com os resultados encontrados no presente estudo (21-25). A análise estatística dos resultados mostra um aumento médio de $10,6 \%$ na concentração da lipoproteína de alta densidade (HDL), com concomitante redução nos níveis de triglicérides (23\%), LDL (40\%) e VLDL
(30\%). Essas variações são condizentes com resultados obtidos na literatura, os quais mostraram uma melhora no lipidograma imediatamente após a realização de maratona e na realização de outros exercícios físicos aeróbicos intensos (22-27).

Considerando que a população analisada era sadia e isenta de problemas renais, a determinação da concentração de creatinina urinária pode servir como medida indireta da atividade do sistema fosfagênio. A análise estatística dos resultados mostra que não houve diferença significativa na concentração de creatinina urinária após a meia maratona $(\mathrm{p}=0,39)$. Por outro lado, a concentração de creatinina plasmática apresentou um aumento significativo após o exercício físico $(\mathrm{p}<0,05)$. Alguns momentos da prova de meia maratona são caracterizados por um aumento na intensidade de contração muscular e da velocidade, ocorrendo um maior recrutamento de fibras musculares do tipo II, além das fibras musculares do tipo I. Apesar de as fibras de tipo II possuírem pouca mitocôndria e pequeno suprimento capilar, têm um maior reservatório de glicogênio e fosfocreatina se comparadas às fibras musculares de tipo I. Assim, por estratégia do atleta, se em algum momento da meia maratona ocorrer um sprint, haverá a necessidade de obtenção de energia a partir da contração muscular rápida por parte da fibra de tipo II. Como consequência, poderá haver uma mobilização das reservas de fosfocreatina para a regeneração de ATP, resultando em uma elevação dos níveis séricos de creatinina. Isso indica que, em decorrência de o esforço aplicado ser essencialmente aeróbico, o sistema fosfagênio é poupado durante a prova e recrutado com maior intensidade em algumas etapas do percurso.

Diversos estudos demonstraram o aumento na concentração sérica de ácido úrico após a realização de exercício físico extenuante (4,28-30), embora Robertson e cols. tenham observado uma redução nos níveis séricos de ácido úrico depois de uma sessão de exercício físico intenso. $\mathrm{O}$ ácido úrico plasmático pode neutralizar radicais peroxil na fase aquosa e contribuir com a defesa antioxidante plasmática. A conversão de hipoxantina em xantina/ácido úrico é catalizada pela xantina oxidase e está associada à formação de íon superóxido, oriundo da semiubequinona da cadeia de transporte de elétrons $(12,28,30)$. A análise estatística dos resultados mostra uma redução significativa na concentração de ácido úrico sérico após a meia maratona ( $\mathrm{p}$ $<0,05)$. Especula-se que a ocorrência dessa hipouricemia possa estar relacionada a um aumento da atividade 
antioxidante (scavenger) do ácido úrico ou à renovação de ATP através da via glicolítica aeróbica, a qual não permite o catabolismo de ATP para formação de ácido úrico. Por outro lado, a concentração de ácido úrico urinário apresentou um aumento significativo após o exercício $(\mathrm{p}<0,05)$, corroborando a ideia de que o decréscimo da concentração plasmática pode estar associado a uma maior excreção urinária.

A análise dos resultados do exame físico da urina mostra que a turbidez apresentou um aumento significativo quando comparado ao repouso $(\mathrm{p}=0,008)$. A perda hídrica não renal (transpiração e evaporação) pode alterar a relação soluto/solvente da urina, excretando uma amostra mais concentrada. Apesar disso, a medida da densidade urinária não apresentou diferença significativa $(\mathrm{p}=0,11)$, indicando que reabsorção de solutos encontrava-se dentro da normalidade (31). A perda hídrica não renal e modificações eletrolíticas são sensivelmente modificadas pelas condições climáticas. A temperatura no dia da prova era de $5^{\circ} \mathrm{C}$, o que pode ter contribuído para minimizar as perdas hídricas não renais que poderiam ser mais exuberantes num dia quente.

Os resultados do exame químico mostram um aumento significativo na proteinúria $(\mathrm{p}<0,001)$, cilindrúria $(\mathrm{p}=0,004)$ e muco $(\mathrm{p}<0,001)$ após esforço. A causa primária dessas alterações pode estar relacionada à atividade física intensa que provoca um variável grau de desidratação, estresse ou distúrbios glomerulares, tubulares e hiperfiltração. Além do aumento da pressão hidrostática durante o exercício, outras causas da elevação de proteínas na urina são: lesão, luxação ou ruptura muscular ocorrida durante a prática desportiva, já que no local da lesão podem ser liberadas proteínas constituintes do tecido local lesado $(7,8,31)$. A presença de filamento de muco e cilindros é decorrente da geleificação da proteína de Tamm Horsfall produzida pelo túbulo renal em condições de estase renal. $\mathrm{O}$ aumento da perda hídrica não renal por evaporação e sudorese promove uma diminuição no fluxo urinário que resulta na formação de cilindros. A quantidade de cilindros geralmente é proporcional à estase urinária $\mathrm{e}$ à desidratação (31). A cilindrúria apresentada concorda com os resultados obtidos por Fasset e cols. Os cilindros do presente estudo apresentaram-se estreitos e curtos, por formação provavelmente no túbulo distal. Essa estase urinária apresentada afastaria a possibilidade de dano glomerular, uma vez que é possível acontecer uma proteinúria transitória sem lesão glomerular ou tubular $(7,8,32)$.
Os resultados também mostram um aumento significativo na presença de sangue na urina $(\mathrm{p}=0,006)$, mas não apresentou diferença na análise microscópica de hemácias $(\mathrm{p}=0,06)$. Além disso, a concentração de ferro sérico livre mostrou uma elevação significativa $(\mathrm{p}=0,028)$, e esse achado pode ser indicativo de hemólise. Exercícios físicos extenuantes podem produzir hemoglobinúria assintomática, em que a hemólise pode ser decorrente do impacto dos pés no solo, aumento da força de cisalhamento do sangue periférico nas paredes dos vasos, decréscimo da concentração de óxido nítrico, bem como estresse oxidativo (12,20,33-35). Por outro lado, os resultados de bilirrubina e urobilinogênio urinário após o esforço não mostraram diferença significativa. De fato, o aumento na destruição eritrocitária produz uma bilirrubinúria tardia, uma vez que esta bilirrubina oriunda da hemólise está na forma não conjugada (apolar), não sendo excretada pelos rins. Além disso, o urobilinogênio é um pigmento resultante da degradação da bilirrubina conjugada pelas bactérias intestinais, que posteriormente é reabsorvido e filtrado pelos rins. Como esse processo pode levar até 24 horas, não foi possível detectá-lo na urina 15 minutos após a prova conforme a proposta do estudo.

Os resultados do eritrograma (eritrometria, hematócrito, hemoglobina, VCM, HCM, CHCM) não mostraram diferença significativa. $\mathrm{O}$ treino de resistência pode provocar uma expansão volêmica, o que justificaria uma queda na concentração de hemoglobina nos atletas. Nesses casos, ocorre um fenômeno reacional e transitório chamado pseudoanemia dilucional $(11,33,34)$, o que não foi o caso. A análise da concentração de ferro sérico e do índice de saturação da transferrina mostrou uma significativa elevação após a prova $(\mathrm{p}<0,05)$. A hiperatividade da cadeia de transporte de elétrons (rica em citocromos), aliada a um variável grau de hemólise, pode promover um extravasamento de proteínas ricas em ferro. Por outro lado, comparando esses resultados à população em geral, encontraram-se valores abaixo da normalidade tanto em repouso como após a meia maratona.

Segundo Mateo e Laínez, indivíduos com valores de hemoglobina dentro da faixa de normalidade, com progressiva redução de ferro sérico (inferior a $60 \mu \mathrm{g} /$ $\mathrm{dL}$ ), aumento da transferrina sérica e redução do percentual de saturação da transferrina (abaixo de 16\%), podem estar na primeira fase de instalação de um processo anêmico. A fase seguinte se caracterizará por reduções importantes da hemoglobina, hematócrito e da 
eritrometria. Isso sugere que, mesmo com níveis normais de hemoglobina, os atletas analisados já apresentam um balanço negativo de ferro, caracterizando uma anemia do atleta e não um quadro de hemodiluição. Esse déficit poderá comprometer o transporte de oxigênio, desencadeando uma perda de rendimento atlético nos indivíduos analisados.

$\mathrm{O}$ aumento da altitude promove uma maior liberação de eritropoietina que, por sua vez, eleva a contagem de eritrócitos e consequentemente de hemoglobina. A meia maratona foi realizada a $600 \mathrm{~m}$ do nível do mar. Não é possível afirmar que esse fator tenha influenciado diretamente os resultados, no entanto, pode ter colaborado para acentuar o quadro de hipoferremia. Assim, faz-se necessária a realização de novos estudos em que esses resultados possam ser comparados a outras provas realizadas ao nível do mar. Independentemente disso, fica clara a necessidade de uma prescrição nutricional adequada, por profissionais capacitados, para suprir as necessidades aumentadas da população analisada.

Análise dos resultados do leucograma mostrou um incremento de aproximadamente $100 \%$ na leucometria pós-esforço $(\mathrm{p}<0,001)$, caracterizada por uma neutrofilia e monocitose. A leucocitose pós-atividade pode ocorrer porque os leucócitos constituem a primeira linha de defesa do organismo diante do estresse físico e ao possível trauma provocado pelo exercício. Essa elevação pode ocorrer em resposta a um aumento na secreção de proteínas de fase aguda, mediadores de resposta inflamatória, catecolaminas, cortisol, hormônio do crescimento $(\mathrm{GH})$, peptídeos opioides (endorfinas), interferons, interleucinas e fatores de necrose tumoral $(20,34,36,37)$.

Considerando o tipo de esforço realizado pelos fundistas durante o percurso de $21 \mathrm{~km}$, a utilização de um grupo controle composto por não atletas torna-se inviável em decorrência de um metabolismo atlético totalmente adaptado a condições extremas de treinamento. Ainda, identificar destaques numa população participante como forma de controlar a variável "tempo de coleta pré e pós-esforço", contar com o aceite em participar do estudo e reconhecê-los dentro de uma multidão participante restringiu a amostra a apenas 20 atletas. O número limitado da amostra não é apropriado para a adoção de valores de referência conclusivos para atletismo, mas contribui para análises sistemáticas de atletas fundistas em situações semelhantes de treino/competição como forma de diferenciação de alterações fisiológicas e patológicas nas condições propostas. A realização de estudos com dosagem de eritropoietina e ferritina poderá auxiliar na distinção de um quadro de hemodiluição, anemia do atleta e hipoferremia.

\section{CONCLUSÃO}

A realização da meia maratona nas condições propostas promoveu uma elevação na atividade de enzimas marcadoras de dano muscular 15 minutos após a prova, podendo ser aplicada com boa confiabilidade. A elevação registrada sugere uma microlesão silenciosa oriunda de um variável grau de rompimento de fibras musculares. Além disso, apesar dos valores de hemoglobina normal, a hipoferremia apresentada pelos atletas indica a instalação de um processo anêmico que poderia evoluir a uma queda nos valores eritrocíticos com subsequente perda de rendimento atlético decorrente de uma oxigenação muscular insatisfatória.

Os resultados do presente estudo permitiram o acompanhamento sistemático dos atletas participantes no monitoramento de lesões silenciosas, rastreamento da anemia do atleta e, além disso, a análise conjunta de dados clínicos dos atletas obtida com o corpo clínico (médico fisiologista, fisioterapeuta, treinadores) possibilitou identificar sinais de desgaste físico como forma de prevenção de perda de rendimento atlético da população analisada. No entanto, os resultados aqui expostos devem ser analisados sob um contexto clínico e jamais como dados numéricos ou como valores de referência.

Agradecimentos: ao Professor Doutor Hugo Tourinho Filho pelas sugestões e revisão do manuscrito.

Declaração: os autores declaram não haver conflitos de interesse científico neste estudo.

\section{REFERÊNCIAS}

1. Monteiro WD, Araújo CGS. Transição caminhada-corrida: considerações fisiológicas e perspectivas para estudos futuros. Rev Bras Med Esporte. 2001;7(6):207-22.

2. Strachan AF, Noakes TD, Kotzenberg G, Nel AE, de Beer FC. Creactive protein concentrations during long-distance running. $\mathrm{Br}$ Med J. 1984;289:1249-51.

3. Febbraio MK, Dancey J. Skeletal muscle energy metabolism during prolonged, fatiguing exercise. J Appl physiol. 1999;87(6):2341-7.

4. De Feo P, Di Loreto C, Lucidi P, Murolo G, Parlanti N, De Cicco A, et al. Metabolic response to exercise. J Endocrinol Invest. 2003;26(9):851-4.

5. Clarkson PM, Hubal MJ. Exercise-induced muscle damage in humans. Am J Phys Med Rehabil. 2002;81(11 Suppl):S52-69.

6. Apple FS, Rogers MA, Ivy JL. Creatine kinase isoenzyme MM variants in skeletal muscle and plasma from marathon runners. Clin Chem. 1986;32(1):41-4.

7. Egermann M, Brocai D, Lill CA, Schmitt H. Analysis of injuries in long-distance triathletes. Int J Sports Med. 2003;24(4):271-6. 
8. Bassit RA, Curi R, Costa Rosa LFBP. Creatine supplementation reduces plasma levels of pro-inflammatory cytokines and PGE2 after a half-ironman competition. Amino Acids. 2008;35(2):425-31.

9. Totsuka M, Nakaji S, Suzuki K, Sugawara K, Sato K. Break point of serum creatine kinase release after endurance exercise. J Appl Physiol. 2002;93(4):1280-6.

10. Yuu H, Ishizawa S, Takagi Y, Gomi K, Senju O, Ishii T. Macro creatine kinase: a study on CK-linked immunoglobulin. Clin Chem. 1980;26(13):1816-20.

11. Fogazzi G, Grignani S. Urine microscopic analysis - an art abandoned by nephrologists? Nephrol DialTransplant. 1998;13(10):2485-7.

12. Chevion S, Moran DS, HeledY, ShaniY, Regev G, Abbou B, et al. Plasma antioxidant status and cell injury after severe physical exercise. Proc Natl Acad Sci. 2003;100(9):5119-23.

13. Echegaray M, Rivera MA. Role of creatine kinase isoenzymes on muscular and cardiorespiratory endurance. Genetic and molecular evidence. Sports Med. 2001;31(13):919-34.

14. Siegel AJ, Sholar M, Yang J, Dhanak E, Lewandrowski KB. Elevated serum cardiac markers in asymptomatic marathon runners after competition: is the myocardium stunned? Cardiology. 1997;88(6):487-91.

15. Siegel AJ, Lewandrowski KB, Strauss HW, Fischman AJ, YasudaT. Normal post-race antimyosin myocardial scintigraphy in asymptomatic marathon runners with elevated serum creatine kinase $\mathrm{MB}$ isoenzyme and troponin T levels. Evidence against silent myocardial cell necrosis. Cardiology. 1995;86(6):451-6.

16. Kratz A, Lewandrowski KB, Siegel AJ, Chun KY, Flood JG, Cott EV. Effect of marathon running on hematologic and biochemical laboratory parameters, including cardiac markers. Am J Clin Pathol. 2002;118(6):856-63.

17. Brites F, Verona J, De Geitere C, Fruchart JC, Castro G, Wikinski R. Enhanced cholesterol efflux promotion in well-trained soccer players. Metabolism. 2004;53(10):1262-7.

18. Bounds RG, Grandjean PW, O'Brien BC, Inman C, Crouse SF. Diet and short term plasma lipoprotein-lipid changes after exercise in trained Men. Int J Sport Nutr Exerc Metab. 2000;10(2):114-27.

19. França SCA, Neto TLB, Agresta MC, Lotufo RFM, Kater CE. Resposta divergente da testosterona e do cortisol séricos em atletas masculinos após uma corrida de maratona. Arq Bras Endocrinol Metabol. 2006,50(6):1082-6.

20. Bounds RG, Grandjean PW, O'Brien BC, Inman C, Crouse SF. Diet and short term plasma lipoprotein-lipid changes after exercise in trained Men. Int J Sport Nutr Exerc Metab. 2000;10(2):114-27.

21. SunamiY, Motoyama M, Kinoshita F, MizookaY, Sueta K, Matsunaga A, et al. Effects of low-intensity aerobic training on the high-density lipoprotein cholesterol concentration in healthy elderly subjects. Metabolism. 1999;48(8):984-8.
22. Hellsten WY, Balson PD, Norman B, Sjodin B. The effect of highintensity training on purine metabolism in man. Acta Physiol Scand. 1993;149(4):405-12.

23. Robertson JD, Maughan RJ, Duthie GG, Morrice PC. Increased blood antioxidant systems of runners in response to training load. Clin Sci. 1991;80(6):611-8.

24. Woitge HW, Friedmann B, Suttner S, Farahmand I, Muller M, Schmidt-Gayk $\mathrm{H}$. Changes in bone turnover induced by aerobic and anaerobic exercise in young males. J Bone Miner Res. 1998;13(12):1797-804.

25. Mastaloudis A, Morrow JD, Hopkins DW, Devaraj S, Traber MG. Antioxidant supplementation prevents exercise-induced lipid peroxidation, but not inflammation, in ultramarathon runners. Free Radic Biol Med. 2004;36:1329-41.

26. Farber HW, Schaefer EJ, Franey R, Grimaldi R, Hill HS. The endurance triathlon: metabolic changes after each event and during recovery. Med Sci Sports Exerc. 1991;23(8):959-65.

27. Pedersen BP, Hoffman-Goetz L. Exercise and the immune system: regulation, integration, and adaptation. Physiol Rev. 2000;80(3):1055-81.

28. Santos RVT, Bassit RA, Caperuto EC, Costa Rosa LFBP. The effect of creatine supplementation upon inflammatory and muscle soreness markers after a $30 \mathrm{~km}$ race. Life Sci. 2004;75:1917-24.

29. Fallon KE, Fallon SK, BostonT.The acute phase response and exercise: court and field sports. Br J Sports Med. 2001;35(3):170-3.

30. Landray MJ, Sagar G, Muskin J, Murray S, Holder RL, Lip GYH. Association of atherogenic low-density lipoprotein subfractions with carotid atherosclerosis. Q J Med. 1998;91:345-51.

31. Noakes TD. Effect of exercise on serum enzyme activities in human. Sports Med. 1987;4(4):245-67.

32. Hansen KN, Bjerre-Knudsen J, Brodthagen U, Jordal R, Paulev PE. Muscle cell leakage due to long distance running. Eur J Appl Physiol Occup Physiol. 1982;48(2):177-88.

33. Brahm H, Piehl-Aulin K, Ljunghall S. Bone metabolism during exercise and recovery: the influence of plasma volume and physical fitness. CalTissue Int. 1997;61(3):192-8.

34. Welsh L, Rutherford OM, James I, Crowley C, Comer M, Wolman $R$. The acute effects of exercise on bone turnover. Int J Sports Med. 1997;18(4):247-51.

35. Mastaloudis A. Antioxidant supplementation prevents exerciseinduced lipid peroxidation, but not infammation, in ultramarathon runners. Free Radic Biol Med. 2004;36(10):1329-41.

36. Mateo RJN, Laínez MGL. Anemia do atleta: fisiopatologia do ferro. Rev Bras Med Esporte. 2000;6(3):108-14.

37. Bonsignore MR, Morici G, Santoro A. Circulating hematopoietic progenitor cells in runners. J Appl Physiol. 2002;12(93):1691-7. 